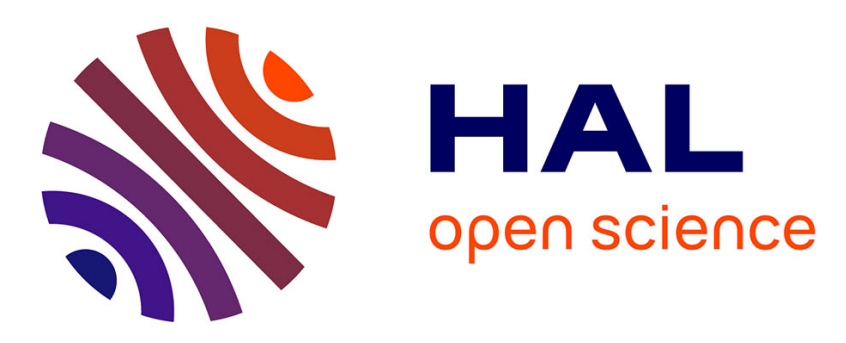

\title{
An experimental method to determine the contact radius changes during a spherical instrumented indentation
}

Jean-Marc Collin, Gérard Mauvoisin, Rochdi El Abdi

\section{- To cite this version:}

Jean-Marc Collin, Gérard Mauvoisin, Rochdi El Abdi. An experimental method to determine the contact radius changes during a spherical instrumented indentation. Mechanics of Materials, 2008, 40, pp.401-406. 10.1016/j.mechmat.2007.10.002 . hal-01005233

\section{HAL Id: hal-01005233 \\ https://hal.science/hal-01005233}

Submitted on 15 Dec 2018

HAL is a multi-disciplinary open access archive for the deposit and dissemination of scientific research documents, whether they are published or not. The documents may come from teaching and research institutions in France or abroad, or from public or private research centers.
L'archive ouverte pluridisciplinaire HAL, est destinée au dépôt et à la diffusion de documents scientifiques de niveau recherche, publiés ou non, émanant des établissements d'enseignement et de recherche français ou étrangers, des laboratoires publics ou privés. 


\title{
An experimental method to determine the contact radius changes during a spherical instrumented indentation
}

\author{
J.-M. Collin*, G. Mauvoisin, R. El Abdi \\ LARMAUR, FRE-CNRS 2717, Bât 10B, Université de Rennes 1, Campus de Beaulieu, 35042 Rennes cedex, France
}

An experimental method to determine contact radius changes during a spherical instrumented indentation test is proposed in this paper. This method is based on the Hertz theory and only depends on the elastic properties of both the indenter and the sample. The programming of several loading, unloading and reloading cycles has allowed the determination of the unloading stiffness changes and consequently the contact radius changes. Numerical results have shown that the proposed method is sensitive to the piling-up or sinking-in. From the contact radius changes we have proposed a new procedure in order to obtain the real indentation load-depth curve from the measured curve. An experimental study has allowed us to validate our procedure during the beginning of the unloading cycle.

Keywords: Spherical indentation; Contact radius changes; Indenter compliance; Friction influence; Experimental measurement

\section{Introduction}

Indentation test, historically used to determine the material hardness, has been developed in order to determine the material mechanical properties since several decades. An instrumented indentation test consists in measuring simultaneously indentation load $P$ and indentation depth $h$ during the penetration of an indenter into a sample. The Meyer's hardness (Meyer, 1908; Tabor, 1951) is then given by the following relationship, where $a$ is the contact radius:

\footnotetext{
* Corresponding author. Tel.: +33223236282.

E-mail address: jean_marc.collin@yahoo.fr (J.-M. Collin).
}

$H=\frac{P}{\pi a^{2}}$.

Many studies have been conducted in order to determine the contact radius. We can separate the different methods in two categories. The first one concerns the determination of the $C^{2}$ factor introduced by Hill et al. (1989). $C^{2}$ quantifies the degree of piling-up $\left(C^{2}>1\right)$ or sinking-in $\left(C^{2}<1\right)$ during the indentation test. A great number of models have been proposed, which are presented in detail in the work of Hernot et al. (2006). The use of $C^{2}$ is restricted by the chosen behaviour law, indeed this factor depends on the sample plasticity properties.

However, the contact radius can be determined through a different method. Li et al. (1997) suggested using the results deduced from the Hertz elastic 
contacts theory (1882) in order to determine the contact radius changes during a Berkovich indentation.

Applying the Hertz theory to indentation allows the determination of a relationship between the indentation load $P$ and depth $h$ in the elastic regime

$P=\frac{4}{3} \frac{E}{1-v^{2}} R^{\frac{1}{2}} h^{\frac{3}{2}}$,

where $v$ is the Poisson ratio. In the case of an elastic indenter, $E /\left(1-v^{2}\right)$ in Eq. (2) has to be replaced by the reduced modulus $E^{*}$

$E^{*}=\left[\frac{\left(1-v_{\mathrm{s}}^{2}\right)}{E_{\mathrm{s}}}+\frac{\left(1-v_{\mathrm{i}}^{2}\right)}{E_{\mathrm{i}}}\right]^{-1}$,

where s stands for "sample" whereas i stands for "indenter". Moreover, in the Hertz theory, the contact radius value is $(R h)^{1 / 2}$, therefore Eq. (2) becomes

$P=\frac{4}{3} \frac{E a h}{1-v^{2}}$.

Galin (1946) proposed a general solution of elastic indentation for every kind of axisymmetric indenters. This solution is sometimes wrongly attributed to Sneddon (1965). Then, Bulychev et al. (1975, 1976); Shorshorov et al. (1981) used this solution in application to indentation test and the initial unloading stiffness can be defined as follows:

$S=\frac{\mathrm{d} P}{\mathrm{~d} h}=2 E^{*} a$.

A complete presentation of these questions is proposed in the paper of Borodich and Keer (2004).

Some methods have been developed to determine the Young modulus from the Hertz theory. We can quote Doerner and Nix (1986); Loubet et al. (1986); Oliver and Pharr (1992).

Concerning the determination of the Young modulus and the hardness, Galanov et al. (1984) proposed another way of determination based on a decomposition of the deformation under the indenter. Models which take into account the plastic deformations are proposed by this author.

$\mathrm{Li}$ et al. (1997) suggested using formula (5) in order not to determine the Young modulus but the contact radius. Their method is based on a modulated loading and unloading cycle for the determination of the instantaneous contact stiffness. Most of the five samples studied were considered as elastic-perfectly plastic. Authors compared experimental measurements with numerical results in the case of a rigid conical indenter. They concluded that Eq. (5) can be applied for the entire indentation cycle. However, comparison made between numerical and experimental results shows that Eq. (5) does not lead to a very accurate determination but to a trend of the contact radius changes. This can be explained by the use of very simple behaviour laws for numerical simulations which do not correspond to the real sample's behaviour. Moreover Eq. (5) does not take into account the radial displacements of material under the indenter.

This aspect has been studied by Galanov (1983); Galanov et al. (1983) who considers a precise formulation of contact problems in order to study the effect of the tangential displacements in the case of conical and pyramidal indenters. In order to determine the contact radius changes during spherical indentation, we suggest using the formulation proposed by Hay and Wolff (2001). They introduced a factor $\gamma$ and the contact stiffness formulation becomes

$S(h)=\frac{\mathrm{d} P}{\mathrm{~d} h}=\frac{2 \gamma E_{\mathrm{s}} a}{1-v_{\mathrm{s}}^{2}}$.

For an elastic spherical indenter, the factor $\gamma$ is defined by the following relationship:

$$
\begin{aligned}
& \gamma=1+\frac{2 a}{3 \pi R}\left[\frac{N\left(1-2 v_{\mathrm{s}}\right)\left(1+v_{\mathrm{s}}\right)}{N\left(1-v_{\mathrm{s}}^{2}\right)+\left(1-v_{\mathrm{i}}^{2}\right)}\right], \\
& N=\frac{E_{\mathrm{i}}}{E_{\mathrm{s}}} .
\end{aligned}
$$

\section{Presentation of the proposed method}

Eqs. (6) and (7) can be turned into a polynomial equation where $a$ is the unknown parameter. Therefore, the resolution gives the following contact radius

$a(h)=\frac{3 \pi R(\sqrt{\Delta(h)}-1)}{4 B}$,

where

$$
\begin{aligned}
& \Delta(h)=1+\frac{4 B\left(1-v_{\mathrm{s}}^{2}\right) S(h)}{3 \pi R E_{\mathrm{s}}}, \\
& B=\left[\frac{N\left(1-2 v_{\mathrm{s}}\right)\left(1+v_{\mathrm{s}}\right)}{N\left(1-v_{\mathrm{s}}^{2}\right)+\left(1-v_{\mathrm{i}}^{2}\right)}\right] .
\end{aligned}
$$

Our method involves several loading, unloading and reloading cycles in order to determine unloading stiffness changes $S(h)$ during the whole unloading 
curves. Lastly, the measurement of the unloading stiffness changes during each unloading cycle allows the determination of contact radius changes with Eqs. (8) and (9).

\section{Numerical study of the contact radius changes}

\subsection{Presentation}

A numerical study has allowed us to validate the proposed method. This study has been conducted in axisymmetric mode with the finite element (FE) code Cast3M. The FE mesh requires the use of several areas with 4-nodes elements and linear interpolation linked with 3-nodes elements areas. Concerning the contact area, the FE mesh requires the use of 8-nodes elements with quadratic interpolation. In the contact area itself, the size of the elements is less than $4 \mu \mathrm{m}$ and the number of the elements used is greater than 4000 . The use of very small elements in the contact area is necessary in order to determine the contact radius with a great accuracy. All samples are simulated with isotropic hardening. The study of the contact radius involves the programming of several loading-unloadingreloading cycles in order to determine the initial unloading stiffness changes $S(h)$ and the unloading stiffness changes during the unloading cycles.

\subsection{Numerical study of the proposed method}

The numerical study of the proposed method is summarized in the case of two representative materials: a steel alloy with high yield stress and a copper alloy with low yield stress. In Figs. 1 and 3 the comparison is made between the contact radius determined by finite elements (written $a(\operatorname{Cast} 3 M)$ ) and the contact radius determined by the proposed method (written $a(S)$ ) during loading and unloading. In Figs. 2 and 4, the square root of $(2 R h)$ evolution (written $\operatorname{Sqrt}(2 R h)$ ) is drawn in order to show the sensitivity of our method to sinking-in or pilingup during loading. Moreover, in these two figures the contact radius changes calculated with $\gamma=1$ (written $a($ gaml $)$ ) is drawn in order to show the veracity of the use of Eqs. (8) and (9).

From numerical indentation curves, the proposed method allows the determination of the contact radius changes during the loading and the unloading cycles (Figs. 1-3), with an average precision greater than $2 \%$. This method is sensitive to the pile-up (Fig. 4) or sink-in (Fig. 2) effect. However,

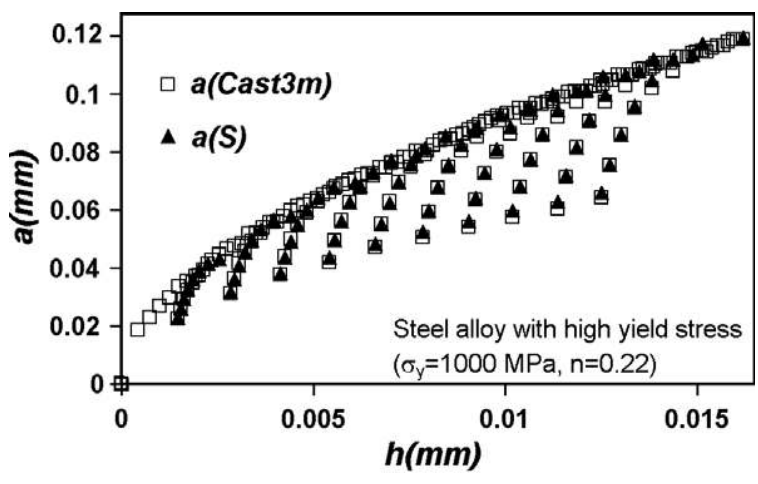

Fig. 1. Application of the proposed method to the first sample.

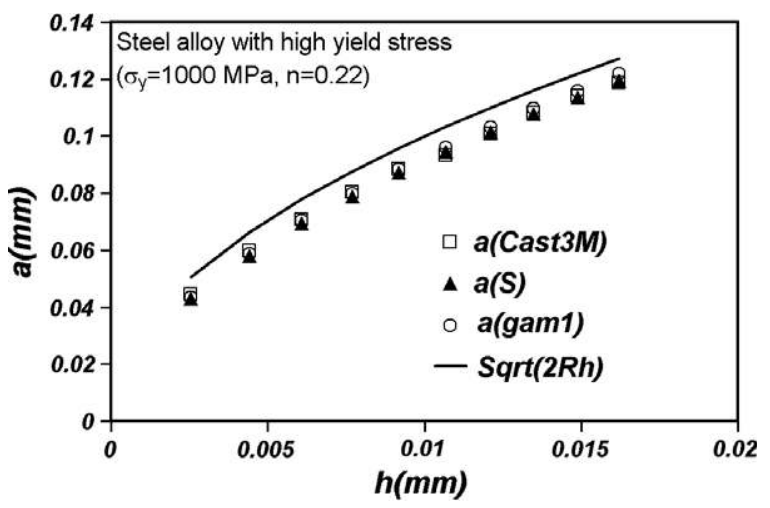

Fig. 2. Sink-in for the first sample.

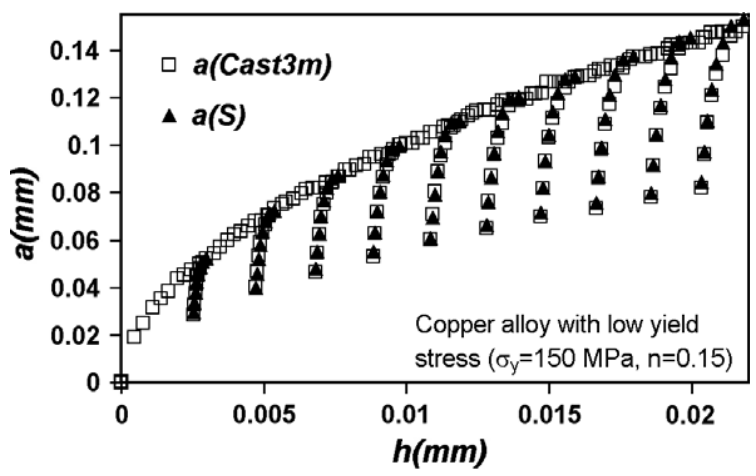

Fig. 3. Application of the proposed method to the second sample.

the method's application is limited by the $a / R$ value. Indeed, Hay et al. established the limit for a rigid indenter at a value of $a / R=0.2$. In the case of an elastic indenter, we have observed that the value of $a / R$ has to be lower than 0.25 . If $a / R$ is higher than 0.25 , Eqs. (8) and (9) will give a worse evaluation of $a(h)$. 


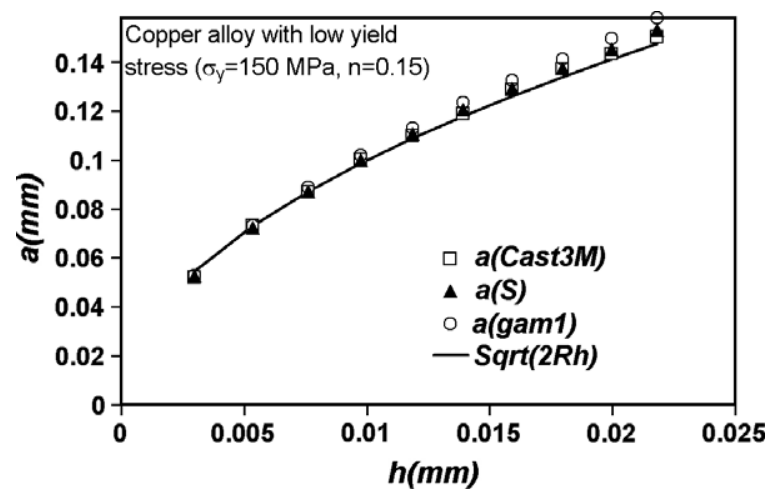

Fig. 4. Pile-up for the second sample.

Concerning the effect of the factor $\gamma$ in the determination of $a(h)$, at the beginning of the indentation test, $a(\operatorname{Cast} 3 M), a(S)$ and $a($ gaml $)$ are quite indistinguishable. However, when the value of $a / R$ increases, the use of $\gamma=1$ overestimates the contact radius. In this case, we can see that the Hay and Wolff correction gives a better evaluation of the contact radius.

\section{Experimental study}

\subsection{Introduction}

Two steel alloys have been selected (a C100 and a C22) because of their microstructure which leads to a good homogeneity. We have developed an experimental bench that allows the measurement of the $P(h)$ curve with a very good reproducibility. The indenter used is made of tungsten carbide. The experimental measured displacement $\left(h_{P 0}\right)$ corresponds to the displacement of the center of the indenter, while the required displacement is the displacement $\left(h_{P 1}\right)$ on the surface of the tested sample (Fig. 5). The difference between the two values of displacement $\left(h_{P 0}\right)$ and $\left(h_{P 1}\right)$ is not that insignificant. This problem is usually corrected by a calibration function, however, this function can cover different phenomena. Moreover, our indenter is not exactly a spherical indenter, then, in order to apply our method, we have defined an equivalent radius which depends on the contact radius evolution $\left(R_{\mathrm{eq}}(a)\right)$.

\subsection{A new procedure to deduce the $P\left(h_{P 1}\right)$ curve} from the $P\left(h_{P 0}\right)$ one

Our numerical study has allowed us to study the deformation of a sphere in contact with a flat surface. In this study, the radial displacements of the vertical axe is fixed to $0: u(r)=0$. All the nodes of the superior line of the indenter have the same displacement and the load is applied on $P_{0}$. The deformation of the sphere leads to the changes of $\delta=h_{P 0}-h_{P 1}$ during the loading and the unloading cycles. From our numerical study, the $\delta$ changes can be described by the following polynomial function (10), depending on the indenter's radius $R$, the contact radius $a$, the load $P$ and the indenter's Young modulus $E$

$$
\begin{aligned}
\delta= & R \quad A+B \frac{P}{\pi R^{2} E_{\mathrm{i}}}+C \frac{P}{\pi a^{2} E_{\mathrm{i}}}+D\left(\frac{P}{\pi R^{2} E_{\mathrm{i}}}\right)^{2} \\
& \left.+E\left(\frac{P}{\pi a^{2} E_{\mathrm{i}}}\right)^{2}+F \frac{P}{\pi R^{2} E_{\mathrm{i}}} \frac{P}{\pi a^{2} E_{\mathrm{i}}}\right)
\end{aligned}
$$

where $A=-1.682 .10^{-5}, \quad B=3.298, \quad C=0.182$, $D=-6446.562, \quad E=-12.727$ and $F=537.889$. From Eqs. (8)-(10), we propose a new procedure

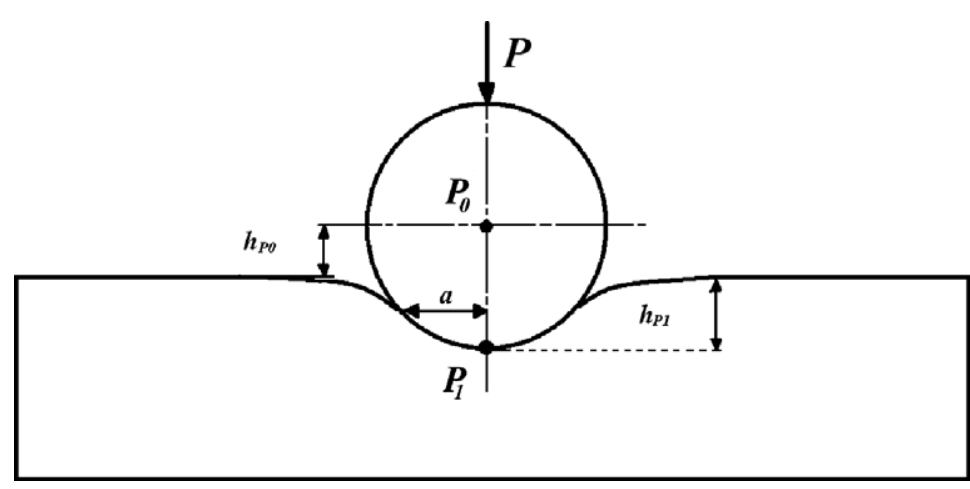

Fig. 5. Difference between measured and wanted displacement. 


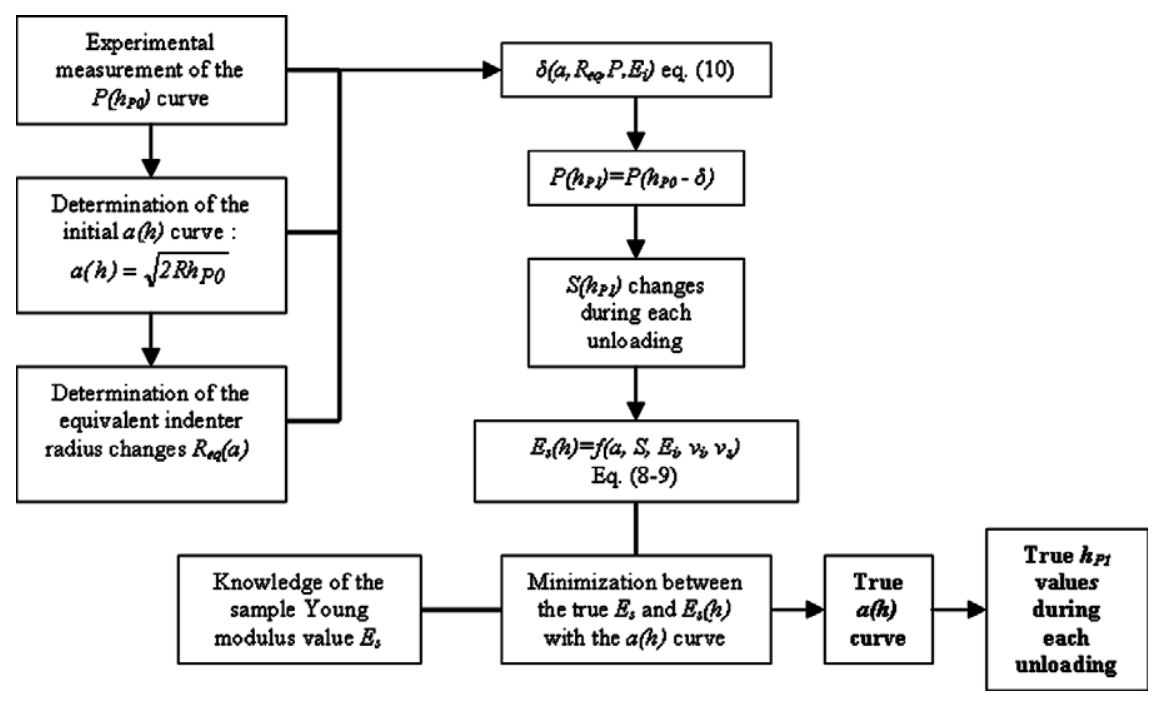

Fig. 6. Procedure to determine the $h_{P 1}$ values during each unloading.

to deduce the $P\left(h_{P 1}\right)$ curve from the $P\left(h_{P 0}\right)$ one, which is presented in Fig. 6:

- the input values are $P\left(h_{P 0}\right)$ and an arbitrary initial $a(h)$ curve;

- from this $a(h)$ curve, we obtain the corresponding radius $R_{\mathrm{eq}}(a)$;

- these three quantities $P\left(h_{P 0}\right), a(h), R_{\text {eq }}(a)$ allow us to calculate the corresponding $\delta(a)$ curve;

- from the $\delta(a)$ curve, we can calculate a $P\left(h_{P 1}\right)$ curve with the relationship $h_{P 1}=h_{P 0}-\delta$;

- Eqs. (8) and (9) unable us to deduce the corresponding values of $E_{\mathrm{s}}$ with $S(h)$ curve calculated from $P\left(h_{P 1}\right)$;

- the knowledge of the true $E_{\mathrm{s}}$ value allows us to find the correct $a(h)$ curve, which minimizes the difference between the calculated $E_{\mathrm{s}}$ and the true value of $E_{\mathrm{s}}$;

- this minimization gives the true $a(h)$ curve and the true $P\left(h_{P 1}\right)$ curve;

From this procedure, we deduce the maximal values of $h_{P 1}$ at the beginning of each unloading. These values are used in Eq. (11) in order to determine the $k$ coefficients for each loading

$k=\frac{\left(h_{P 1 \max }-h_{P 0 \max }\right)}{P_{\max }}$.

Thus, the $h_{P 1}$ values during each loading are given by

$h_{P 1}=h_{P 0}+k P$.

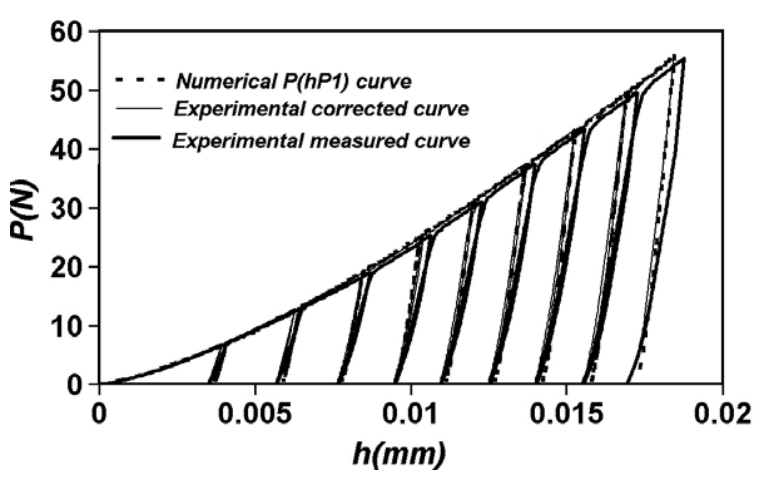

Fig. 7. Experimental determination of $P\left(h_{P 1}\right)$ from $P\left(h_{P 0}\right)$ for a C22 steel.

\subsection{Experimental determination of $a(h)$ curve}

Our procedure described in Section 4.2 has been applied in order to obtain the $P\left(h_{P 1}\right)$ curve from the $P\left(h_{P 0}\right)$ curve. As shown in Fig. 7 , we obtain a very good correction of the loading curve, although we observe some differences between the experimental and the numerical unloading curves. An explanation of these differences may be the kinematic hardening influence.

These differences do not allow the comparison between $a(h)$, obtained from Eqs. (8) and (9), and theoretical $a(h)$, since theoretical $a(h)$ is not known during the whole unloading curve. Nevertheless, we can compare theoretical $a(h)$ and the one obtained from our procedure at the beginning of the unloading curve. Figs. 8 and 9 show the applica- 


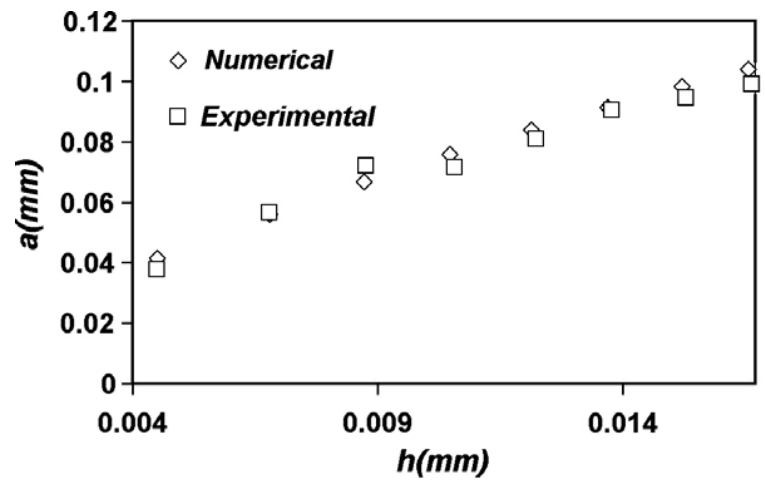

Fig. 8. Determination of $a(h)$ for a C100 steel.

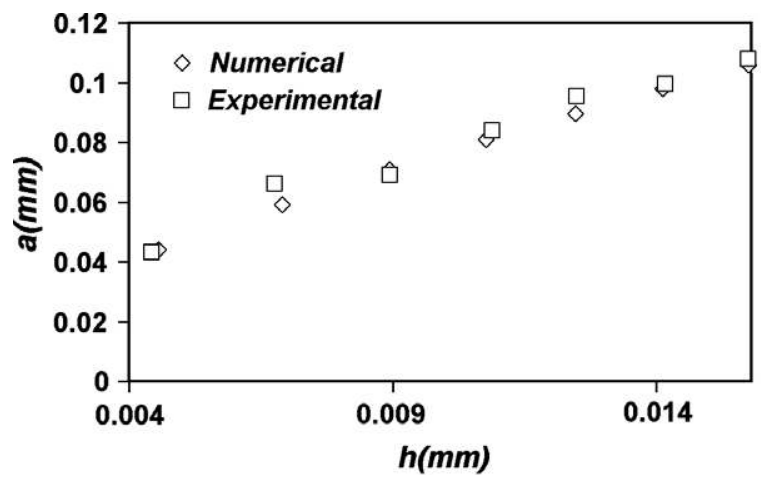

Fig. 9. Determination of $a(h)$ for a C22 steel.

tion of our procedure to determine the contact radius's highest values for the different unloading cycles. These two experimental examples show that our procedure allows the determination of the $a(h)$ curve with an average precision better than $5 \%$.

\section{Conclusion}

A numerical study has allowed us to validate a method to determine the contact radius changes during the unloading process in spherical indentation. It is shown that the Hay and Wolff correction leads to a more accurate determination of the contact radius than the existing method.

From our procedure, the knowledge of both indenter and sample elastic properties leads to the required load-depth curve and to the contact radius changes during a spherical indentation test.

\section{Acknowledgement}

This research was sponsored by the French government as well as the Brittany Region.

\section{References}

Borodich, F.M., Keer, L.M., 2004. Contact problems and depthsensing nanoindentation for frictionless and frictional boundary conditions. Int. J. Solids Struct. 41, 2479-2499.

Bulychev, S.I., Alekhin, V.P., Shorshorov, M.Kh., Ternovskii, A.P., Shnyrev, G.D., 1975. Determining young's modulus from the indenter penetration diagram. Zavod Lab. 41.

Bulychev, S.I., Alekhin, V.P., Shorshorov, M.Kh., Ternovskii, A.P., 1976. Mechanical properties of materials studied from kinetic diagrams of load versus depth of impression during microimpression. Strength Mater. 8, 1084-1089.

Doerner, M.F., Nix, W.D., 1986. A method for interpreting the data from depth-sensing indentation instruments. J. Mater. Res. 1.

Galanov, B.A., 1983. Statement and solution of some more precise problems of elastic contact of two bodies. Izv. AN SSSR. Mekhanika Tverdogo Tela 18 (6), 53-56.

Galanov, B.A., Grigor'ev, O.N., Mil'man, Yu.V., Ragozin, I.P., 1983. Determination of the Hardness and Young's modulus from the depth of penetration of a pyramidal indentor. Problemy Prochnosti 11, 93-96.

Galanov, B.A., Grigor'ev, O.N., Mil'man, Yu.V., Ragozin, I.P., Trefilov, V.I., 1984. Determination of the hardness and Young's modulus with elastoplastic penetration of indentors into materials. Sov. Phys. Dokl. 29 (2), 146-147.

Galin, L.A., 1946. Spatial contact problems of the theory of elasticity for punches of circular shape in planar projection. J. Appl. Math. Mech. (PMM) 10, 425-448.

Hay, J.C., Wolff, P.J., 2001. Small correction required when applying the Hertzian contact model to instrumented indentation data. J. Mater. Res. 16 (5), 1280-1286.

Hernot, X., Bartier, O., Berkouche, Y., El Abdi, R., Mauvoisin, G., 2006. Influence of penetration depth and mechanical properties on contact radius determination for spherical indentation. Int. J. Solids Struct. 43 (14-15), $4136-4153$

Hertz, H., 1882. Uber die Berührung festischer Körper. Z. Reine Angew. Math. 92, 156-171.

Hill, R., Stôrackers, B., Zdunek, A.B., 1989. A theoretical study of the Brinell hardness test. Proc. Roy. Soc. Lond. A 423, 301-330.

Li, K., Wu, T.W., Li, J.C.M., 1997. Contact area evolution during an indentation process. J. Mater. Res. 12 (8), 2064 2071.

Loubet, J.L., Georges, J.M., Meille, G., 1986. Vickers indentation curves of elastoplastic materials. Microindentation tech. In: Mat. Sci. Eng., ASTM STP 889.

Meyer, E., 1908. Untersuchen über Härteprüfung und Härte. Z. des Ver. Deut. Ingenieure 52, 645-654.

Oliver, W.C., Pharr, G.M., 1992. An improved technique for determining hardness and elastic modulus using load and displacement sensing indentation experiments. J. Mater. Res. 7 (6), 1564-1583.

Shorshorov, M.Kh., Bulychev, S.I., Alekhin, V.P., 1981. Work of plastic and elastic deformation during indentation. Sov. Phys. Dok1. 26, 769-771.

Sneddon, I.N., 1965. The relation between load and penetration in the axisymmetric Boussinesq problem for a punch of arbitrary profile. Int. J. Eng. Sci. 3.

Tabor, D., 1951. The Hardness of Metals. Clarendon Press, Oxford, UK. 